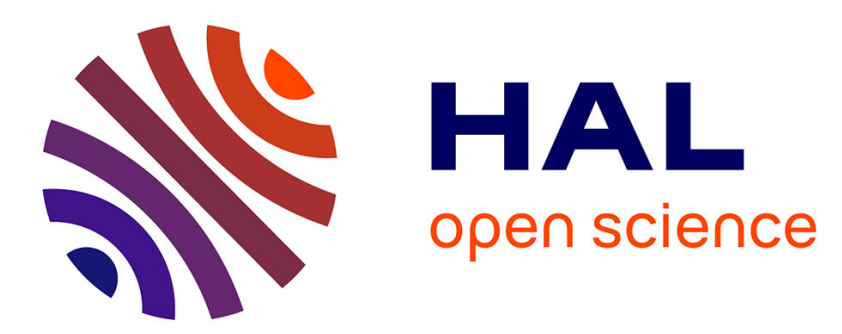

\title{
Kinetics of Austenite to Martensite Transformations in Iron-Nickel-Carbone Alloys During their Cooling or Tensile Testing
}

I. Kozelkova, C. Dagbert, P. Gregoire, J. Galland, L. Hyspecka

\section{- To cite this version:}

I. Kozelkova, C. Dagbert, P. Gregoire, J. Galland, L. Hyspecka. Kinetics of Austenite to Martensite Transformations in Iron-Nickel-Carbone Alloys During their Cooling or Tensile Testing. Journal de Physique IV Proceedings, 1995, 05 (C8), pp.C8-323-C8-328. 10.1051/jp4:1995846 . jpa-00254095

\section{HAL Id: jpa-00254095 https://hal.science/jpa-00254095}

Submitted on 1 Jan 1995

HAL is a multi-disciplinary open access archive for the deposit and dissemination of scientific research documents, whether they are published or not. The documents may come from teaching and research institutions in France or abroad, or from public or private research centers.
L'archive ouverte pluridisciplinaire HAL, est destinée au dépôt et à la diffusion de documents scientifiques de niveau recherche, publiés ou non, émanant des établissements d'enseignement et de recherche français ou étrangers, des laboratoires publics ou privés. 


\title{
Kinetics of Austenite to Martensite Transformations in Iron-Nickel-Carbone Alloys During their Cooling or Tensile Testing
}

\author{
I. Kozelkova, C. Dagbert, P. Gregoire, J. Galland and L. Hyspecka* \\ Ecole Centrale Paris, 92295 Châtenay-Malabry, France \\ * Technical University of Minning, 70800 Ostrava, Czech Republic
}

\begin{abstract}
Two austenitic Fe-Ni-C alloys, one having $23.9 \mathrm{wt} . \% \mathrm{Ni}, 0.39 \mathrm{wt} . \% \mathrm{C}$, and a martensit start point of $228 \mathrm{~K}$, the other with $21.8 \mathrm{wt} . \% \mathrm{Ni}, 0.48 \mathrm{wt} . \% \mathrm{C}$, and an $\mathrm{M}_{\mathrm{S}}$ of $233 \mathrm{~K}$, were tested to determine the

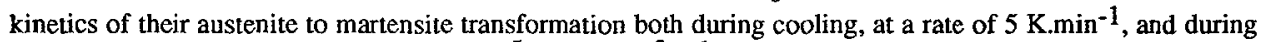
tensile testing at strain rates from $8.3 \times 10^{-5}$ to $8.3 \times 10^{-3} \mathrm{~s}^{-1}$ and at temperatures from 233 to $323 \mathrm{~K}$. Both alloys displayed variations in the critical plastic strain $\varepsilon_{\mathrm{c}}$ for the onset of serrated yielding. Metallography confirmed that serrated yielding can occur in austenite before any strain-induced martensite is formed. Although strain-induced martensite formed at all of the examined strain rates and temperatures, inflections on the true stress versus true strain, or $\sigma-\varepsilon$ diagrams, were observed only at low test temperatures. The effect of transformation-induced plasticity, or TRIP, assessed by the maxima of uniform plastic strain $\varepsilon_{\mathfrak{u}},\left(\varepsilon_{\mathfrak{u}}=0.8\right)$, was detected only in tests run at 253,273 and $293 \mathrm{~K}$. Kinetic diagrams for the formation of strain-induced martensite, in dependence on $\varepsilon$, were compiled for all the test temperatures and strain rates, and were compared with kinetic diagrams of heat release gained by differential scanning calorimetry for the austenite to martensite transformation. Diagrams of the amounts of heat released, $\Delta \mathrm{Q}^{\mathrm{A} \rightarrow \mathrm{M}}$, in the martensite formation process, against the plastic strain magnitude in the presence of similar proportions of martensite, were found to yield linear relationship.
\end{abstract}

\section{INTRODUCTION}

Martensite transformations are often investigated on $\mathrm{Fe}-\mathrm{Ni}-\mathrm{C}$ alloys, where the process kinetics can be studied by relatively simple experimental procedures $(1,2,3)$. Martensite arises either by quenching to below the martensite start temperature $M_{S}$, or else by strain $\varepsilon$ at a temperature above $M_{S}$ but below the thermodynamic equilibrium temperature $\mathrm{T}_{0}$. The work reported here examined the kinetics of martensite transformations induced by both of these alternative means, and shows how the findings can be compared.

\section{EXPERIMENTAL WORK}

This research was performed on two alloys, designated A and B respectively, with the chemical compositions and $\mathrm{M}_{\mathbf{S}}$ temperatures listed in Table 1.

\begin{tabular}{|c|c|c|c|c|c|c|c|}
\hline Alloy & $\% \mathrm{C}$ & $\% \mathrm{Ni}$ & $\% \mathrm{Si}$ & $\% \mathrm{P}$ & $\% \mathrm{~S}$ & $\% \mathrm{Mn}$ & $\mathrm{M}_{\mathrm{S}}[\mathrm{K}]$ \\
\hline $\mathrm{A}$ & 0,39 & 23,87 & 0,44 & 0,0070 & 0,020 & 0,42 & 228 \\
\hline $\mathrm{B}$ & 0,48 & 21,80 & 0,35 & 0,0060 & 0,019 & 0,43 & 233 \\
\hline
\end{tabular}

Table 1: Compositions and $M_{S}$ points of the examined alloys 
The preparation and processing of the specimens have been described previously $[4,5]$. Their two stage austenitizing treatment produced a homogeneous austenitic structure and a mean grain size of $0.080 \mathrm{~mm}$.

Alloy A was utilised to ascertain the kinetics of martensite transformations induced by quenching and by strain, and to compare them. Quenching was performed in a Setaram DSC 111 calorimeter at a cooling rate of $5 \mathrm{~K} \cdot \mathrm{min}^{-1}$ from room temperature down to $153 \mathrm{~K}$. The calorimetry records then yielded heat diagrams showing the amounts of energy released during the transformation process, and integration revealed the amounts of energy released in the formation of a given quantity of martensite in quenching down to $153 \mathrm{~K}$. The quantity of martensite formed by this quench was established by metallography, by a point-to-point method.

If we assume that the amount of heat liberated in the formation of each per cent of martensite remains constant throughout the transformation process, then the total amount of heat $\Delta \mathrm{Q}$ released between $153 \mathrm{~K}$ and $M_{S}$ by the formation of some per cent of $\alpha^{\prime} \mathrm{T}$ martensite can be established as :

$$
\Delta Q_{\left(q_{c} \alpha^{\prime}\right)_{\mathrm{T}}}=\frac{\Delta \mathrm{Q}_{153 \mathrm{~K}}}{\% \alpha_{153 \mathrm{~K}}^{\prime}} \% \alpha_{\mathrm{T}}^{\prime}
$$

This equation then allows us to compile kinetic diagrams for martensite transformations in terms of the amounts of energy $\Delta Q$ versus the percentages of $\alpha_{T}^{\prime}$ martensite.

The kinetics of strain-induced martensite transformations were examined by tensile tests at a strain rate of $8.33 .10^{-4} \mathrm{~s}^{-1}$ and test temperatures ranging from -40 to $+50^{\circ} \mathrm{C}(233$ to $323 \mathrm{~K}$ ). To permit the construction of kinetic diagrams, we conducted both conventional tensile tests to rupture, and interrupted tests in which the specimens were subjected to only a certain amount of plastic strain and then unloaded . The proportions of martensite were then determined in all the specimens, always in the regions which had undergone only uniform strain without any necking.

Alloy B was used to investigate how the strain rate $\dot{\varepsilon}$ and the test temperature affect the martensite transformation. Tensile testing was carried out at strain rates of $\dot{\varepsilon}_{1}=8.33 .10^{-3} \mathrm{~s}^{-1}, \dot{\varepsilon}_{2}=8.33 .10^{-4} \mathrm{~s}^{-1}$ and $\dot{\varepsilon}_{3}=8.33 .10^{-5} \mathrm{~s}^{-1}$ and test temperatures of $\mathrm{T}_{1}=20^{\circ} \mathrm{C}(293 \mathrm{~K}), \mathrm{T}_{2}=5^{\circ} \mathrm{C}(278 \mathrm{~K})$ et $\mathrm{T}_{3}=-20^{\circ} \mathrm{C}$ $(253 \mathrm{~K})$.

\section{RESULTS}

Fig.1 presents heat release diagrams showing the enthalpy of a martensite transformation, as obtained by calorimetry. The transformation will be seen to have a "burst" character. The $\mathrm{M}_{\mathrm{S}}$ temperatures were always ascertained at the points where the bursts arose. In the first case, $M_{S}$ was $216 \mathrm{~K}\left(-57^{\circ} \mathrm{C}\right)$, in the second case, it was $213 \mathrm{~K}\left(-60^{\circ} \mathrm{C}\right)$.
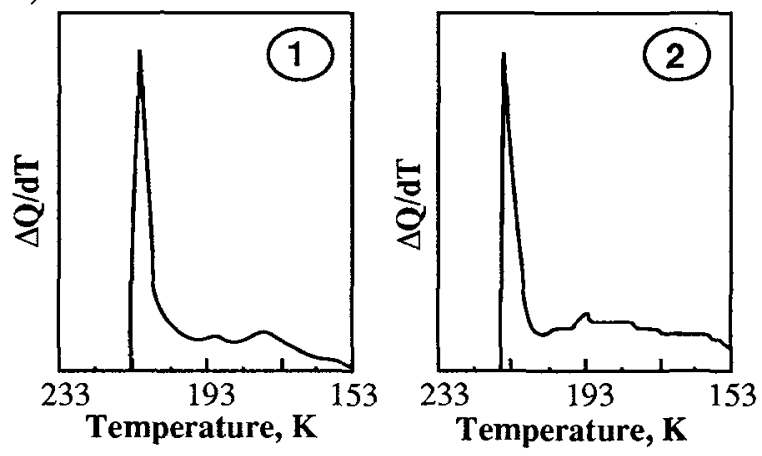

Fig. 1 : Heat release diagrams for the enthalpy of alloy $A$ in specimens 1 and 2. 
Fig. 2 indicates the kinetics of martensite transformations. It will be noted that a burst causes very rapid onset of the transformation (some 20 to $30 \%$ of martensite arise during cooling by roughly $10 \mathrm{~K}$ beneath the $M_{S}$ point), and that later this process slows down.

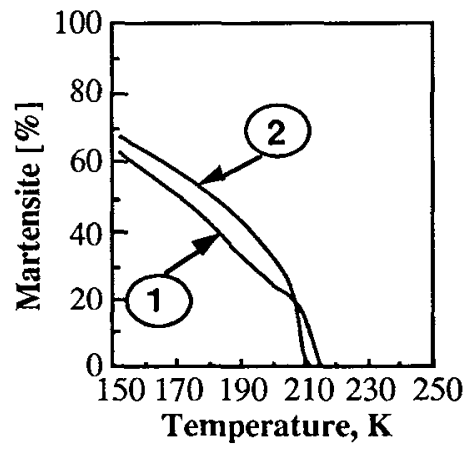

Fig. 2 : Kinetics of quench-induced martensite transformation in alloy A, specimens 1 and 2.

The $\mathrm{M}_{\mathbf{S}}$ temperature ascertained by calorimetry is lower than that established by metallography. It has been thought to be due to the stabilization of austenite by its slow cooling $[6,7]$ in the calorimeter, as against its more rapid cooling in metallographic tests.

The kinetics of strain-induced martensite transformations were examined at four temperatures : 233, 253, 293 and $323 \mathrm{~K}$, or $-40,-20,+20$ and $+50^{\circ} \mathrm{C}$. The findings are summarized in Fig. 3.

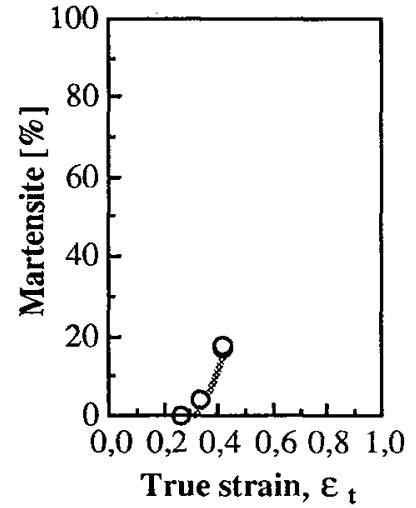

a)

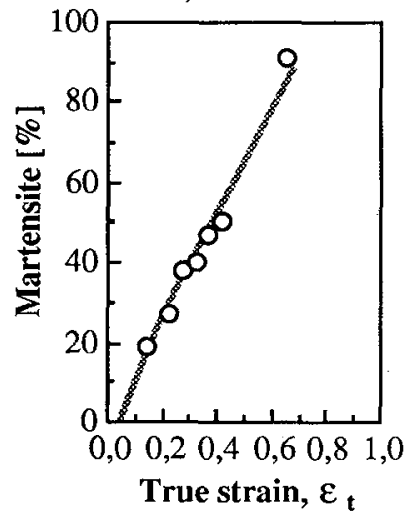

c)

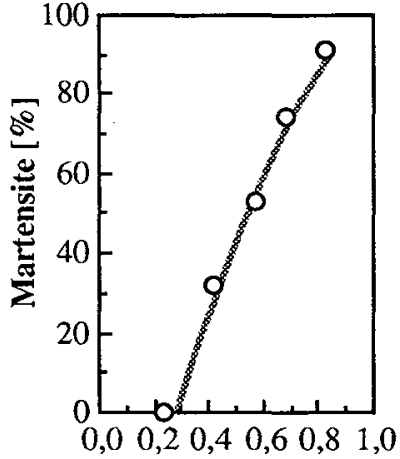

True strain, $\varepsilon_{t}$

b)

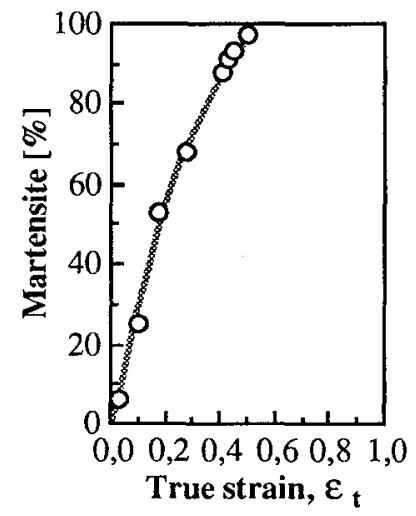

d)

Fig. 3 : Kinetics of strain-induced martensite transformations at test temperatures of : a) $323 \mathrm{~K}$, b) $293 \mathrm{~K}$, c) $253 \mathrm{~K}$, and d) $233 \mathrm{~K}$. 
The shape of the curves in these diagrams is much the same regardless of the test temperature; what alters is the instant when the martensite transformation begins. At a temperature very close to $\mathrm{M}_{\mathrm{S}}$, at $233 \mathrm{~K}$ or $-40^{\circ} \mathrm{C}$, the transformation begins immediately upon the onset of plastic strain. The higher the test temperature, the more plastic strain is needed before the transformation starts, and the less martensite is produced.

Fig. 4 affords a comparison of the kinetics of quench-induced and of strain-induced martensite transformations. In this diagram, the amount of heat released during the transformation (on the $y$ axis) is plotted against the strain required for the formation of an equal amount of martensite (on the $\mathrm{x}$ axis).

Apart from the onset of martensite transformation, which varies with the test temperature, there is a linear relationship between the quantity of heat released in quench-induced transformations and the amount of strain needed for strain-induced martensite to arise at any given test temperature. If the test temperature is taken into account, this relationship can be described by

$$
\Delta \mathrm{Q}=-2609+1693 . \varepsilon+667505 \cdot \frac{1}{\mathrm{~T}}\left[\mathrm{~J} \cdot \mathrm{mol}^{-1}\right]
$$

Tensile testing at some of the applied temperatures produced evidence of a TRIP or transformationinduced plasticity effect. Fig. 5 shows that at temperatures close to $\mathrm{M}_{\mathrm{S}}$, in our case $233 \mathrm{~K}$, we gain a large amount of martensite (about $96 \%$ ), but that this transformation does not enhance plasticity. At temperatures very far from $\mathrm{M}_{\mathrm{S}}$, such as $323 \mathrm{~K}$, we obtain only a little amount of martensite (roughly 18\%), but plasticity is not improved either. Only at test temperatures between these two extremes, i.e. at 253,273 and $293 \mathrm{~K}$, did we obtain some 80 to $90 \%$ of martensite while plasticity rose approximately from 0,4 to 0,8 .

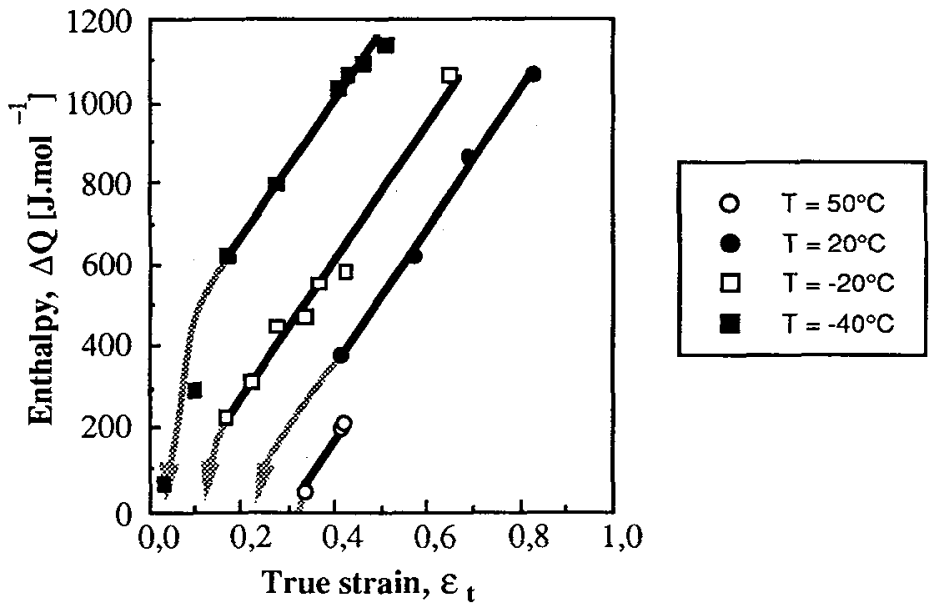

Fig. 4 : A comparison of the kinetics of quench-induced and of strain-induced martensite transformations.

The TRIP effect became apparent only in the temperature interval between $\mathrm{Ms}+25$ and $\mathrm{Ms}+65$, and only at a strain rate of $8.33 \times 10^{-4} \mathrm{~s}^{-1}$.

Inflection point $\varepsilon_{\mathrm{i}}$ on the rational $\sigma_{\mathrm{t}}-\varepsilon_{\mathrm{t}}$ curve is sometimes claimed to be related to the onset of a strain-induced martensite transformation [8]. In our tests at $323 \mathrm{~K}$ no inflection was observed, and the ruptured specimen was found to contain $17 \%$ of martensite. Lower test temperatures always resulted in an inflection, but that did not mark the start of martensite transformation, because at this point the transformation was already in progress : at $293 \mathrm{~K}, \varepsilon_{\mathrm{i}}=33 \% \alpha_{\mathrm{D}}$; at $\mathrm{T}=253 \mathrm{~K}, \varepsilon_{\mathrm{i}}=19 \% \alpha_{\mathrm{D}}$; and at $\mathrm{T}=233 \mathrm{~K}, \varepsilon_{\mathrm{i}}=68 \% \alpha_{\mathrm{D}}$ ). The inflection on the $\sigma_{\mathrm{t}}-\varepsilon_{\mathrm{t}}$ diagram merely indicates that the material contains 
enough martensite for its mechanical properties to alter : it does not signal the onset of martensite transformation.

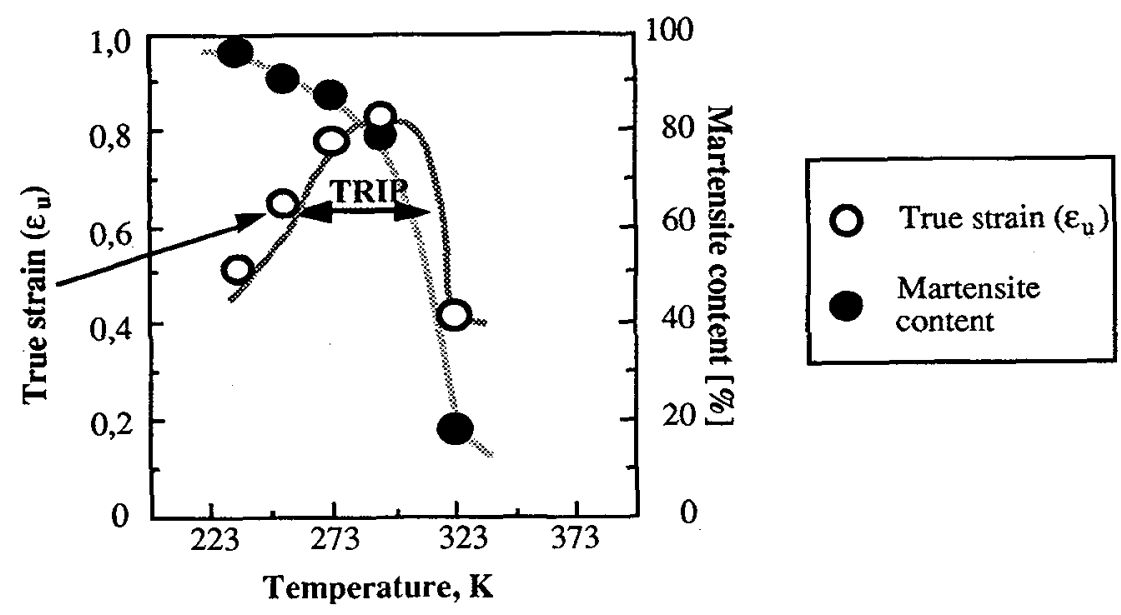

Fig. 5 : Strain and the amount of martensite formed as functions of the test temperature.

The tensile test records also revealed some serrated yielding ; its initial stages, at $\varepsilon_{c}$, were observed both in the purely austenitic, as yet untransformed structures at 323 and $293 \mathrm{~K}$, and in structures already undergoing martensite transformations : at $253 \mathrm{~K}, \varepsilon_{\mathrm{c}}=19 \% \alpha_{\mathrm{D}}$ and at $233 \mathrm{~K}, \varepsilon_{\mathrm{c}}=88 \% \alpha_{\mathrm{D}}$.

Fig. 6 demonstrates the test temperature dependence of $\varepsilon_{c}$ in alloy $A$ at one strain rate, $8.33 \times 10^{-4} \mathrm{~s}^{-1}$, and Fig. 7 shows the same dependence in alloy $B$ at three different strain rates. The evidence is that $\varepsilon_{c}$ declines as the temperature increases and as the strain rate diminishes.

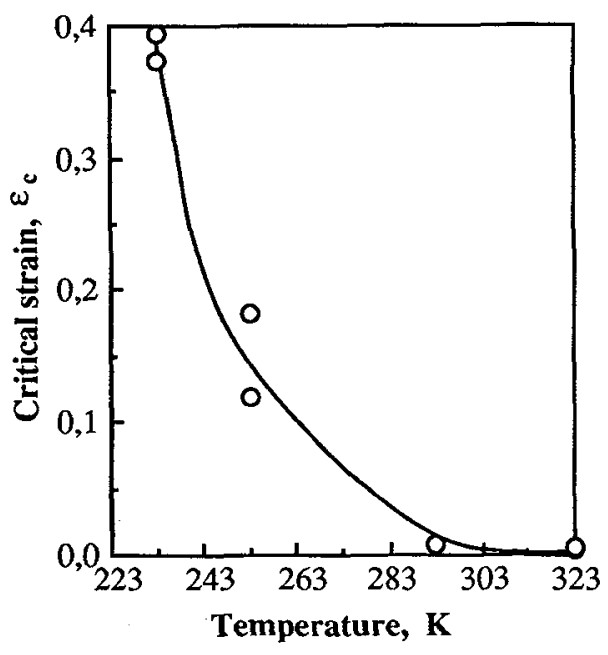

Fig. 6 : Temperature dependence of the critical strain that starts serrated yielding in alloy $\mathrm{A}$.

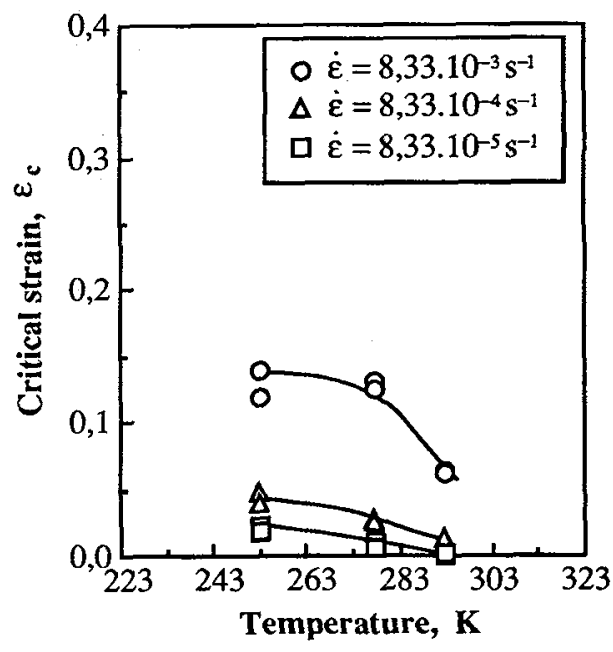

Fig. 7 : Temperature and strain rate dependences of the critical strain for the start of serrated yielding in alloy $B$. 


\section{DISCUSSION AND CONCLUSION}

In this work, we determined the relationship between the kinetics of quench-induced and of straininduced martensite transformations. An equation presented here describes the relationship between the enthalpy liberated in the formation of a certain amount of quench-induced martensite, and the strain needed to produce the same amount of strain-induced martensite at the same test temperature (above the $\mathbf{M}_{\mathbf{S}}$ point).

This relation does not apply to the initial phase of the martensite transformation : it becomes valid only from strains of about 0.2 upwards. Below this threshold of 0.2 , the computed $\Delta Q$ values are higher than the real level.

In alloy A, a TRIP effect was discerned in the temperature interval between $M_{S}+25$ and $M_{S}+65$, but it did not become apparent at test temperatures close to $M_{S}$; strain easily produced large proportions of martensite, about $96 \%$, but the final amount of strain was roughly equal to that observed at test temperatures far from the $\mathbf{M}_{\mathbf{S}}$ point, at which strain temperatures rendered only little martensite (about $18 \%$ ). The martensite transformation enhances plasticity only at temperatures which lie between these two extremes, improving it to as much as 0.8 .

This investigation failed to define the onset of strain-induced martensite transformation from charts recorded during tensile testing or from rational diagrams. Inflection points on the rational $\sigma_{t}-\varepsilon_{t}$ diagrams appeared only at a stage when the specimen already contained $19 \%$ or more of martensite; at $323 \mathrm{~K}$ no inflection was discovered, yet a ruptured specimen was found to hold $17 \%$ of martensite.

The onset of serrated yielding, at $\varepsilon_{\mathrm{c}}$, does not signal the start of martensite transformation : serrated yielding was detected in both austenitic and martensitic structures.

\section{References}

[1] Lin M., Olson G.B. and Cohen M., Metallurgical Transactions A 23A (1994) 2987-2998.

[2] Tamura I., Metal Science 16 (1992) 245-253.

[3] Zhang X.M., Li D.F., Xing Z.S., Gautier E., Zhang J.S. and Simon A., Acta metall. mater. 41 (1993) 1693-1699.

[4] Sehili M., Doctorat Thesis, ECP Paris 1994

[5] Grégoire P., Dagbert C., Pahuta P., Galland J. and Hyspecká L., Materials Science Forum 56-58 (1990) 213-218

[6] Okamato M., Odaka R., Nippon Kinzoku 16 (1952) 81-87

[7] Zeo R.B.G., Trans AIME 224 (1962) 1222-1228

[8] Lacombe P., "Rappels de métallurgie", Corrosion sous contrainte : phénoménologie et mécanismes, Bombannes 1990, D. Desjardins and R. Oltra Eds. (Les éditions de physique) pp. 129-157 